\title{
Effect of Lap Joint Width to the Shear and Peel Stress Distribution of Bi-Adhesive
}

\author{
Witono Hardi*, Rudi Hartono \\ Departemnt of Mechanical Enginerring, Universitas Khairun, Ternate, Indonesia
}

\begin{abstract}
A single lap joint is one of the most popular types of adhesive joints. This joint is very easy to apply and gives satisfactory results. However, there is an extensive shear stress distribution at both ends in a single lap joint and shallow in the middle. In this research, the performance test of the bi-adhesive with different joint widths was carried out. We modelled with 2D FEM consisting of adherent aluminum, two adhesives DP490 and ESP110 and then performed a static test to obtain shear and peel stress distribution. The results presented that using a bi-adhesive improved the shear stress distribution compared to a single adhesive individually. By adjusting the length ratio of each adhesive, the optimum conditions will be obtained. The peak stress will decrease, and the stress distribution will be better. In addition, the wider the lap joint, the stress distribution will be more evenly distributed. The peak stresses at the ends and in the middle of the joint are getting smaller in both the single adhesive individually and the bi-adhesive. This result is a recommendation for the user to increase the strength of the adhesive joint.
\end{abstract}

Keyword: Adhesive, adhesive joint, FEM simulation, shear stress, distribution

\section{Introduction}

The fastener is a method for merging one component with other components. We are generally familiar with mechanical fasteners such as welded joints, rivet and bolted joints. This joining has been used for a very long time. The adhesive joint is advanced and provides advantages such as uniform stress distribution, wide joint surface and ease of connection of different types of materials, both similar and dissimilar. The adhesive bond relies on the adhesion properties between the adherent (the joined part) and the adhesive (glue or epoxy). This joining is very widely used today because it has better advantages than mechanical fasteners. Adhesive joint more even distribution of stress, eliminates stress concentrations, can connect dissimilar materials, good surface finishing, functions as a sealant and reduces noise and vibration. Adhesives are widely used in manufacturing, automotive, aircraft to defence equipment. Its use is practical, neat and reduces the number of parts to be connected. Adhesive joints have many advantages over mechanical joints in reducing the weight of the entire construction.

However, the development and research of adhesive joint problems are always carried out to further increase its advantages and capabilities and minimize its disadvantages and weaknesses. Many previous researchers have carried out modifications to the adhesive joint, such as modification of thickness and area, improvement of the ratio of epoxy to hardener mixture, adding silicate grains, and performing surface treatment to improve the mechanical bond between the material being joined with the adhesive.

The lap joint is the most popular connection. Its easy use and good strength are some of the reasons. In the lap joint, there is an uneven distribution of shear stress along the bond line. Generally, very large at the ends and very low in the middle.

In this study, two adhesives with different modulus of elasticity were joint. An adhesive with a low modulus of elasticity is placed at the end of the joint, while a stiffer adhesive is placed in the middle. It is expected that there will be improvements in the distribution of shear stress and peel stress which can increase the strength of the connection.

\section{Literature Review}

The use of adhesives as joints in the industry has been going on for a long time [1]. Its development from year to year is getting more satisfying. Adhesive joints provide good advantages over conventional mechanical fasteners.

The advantage of adhesive joints is that they can connect materials of the same type (similar) or different types (dissimilar). One example of the use of dissimilar joints is on ships. In this case, the adhesive acts as a connection as well as a sealant [2]. Today's automotive uses a new adhesive technology that works at various load levels and temperatures without damaging the joint

\footnotetext{
* Corresponding author : witono@unkhair.ac.id
} 
[3]. Another adhesive capability is that it is easy to make multi-material joints. This usually happens in the vehicle industry [4]. In automotive, adhesives that can absorb impact energy are needed [5].

The type of connection, the adhesive and other variables significantly affect the behaviour of the adhesive. The type of adhesive also dramatically affects the condition of the joining [6]. The placement of adhesive between the adherents also greatly affects its strength. In single lap joints, misalignment will reduce strength [7]. Lap joint testing on impact loading gives different results when compared to quasi-static conditions. Under impact loading, the lap joint strength will increase compared to quasi-static [8].

The use of numerical methods to analyze adhesive joints has been around for a long time. [9] At the same time, experiments were also carried out to validate the simulation results.

The adhesive thickness affects the joint behaviour when carried out under impact and static loading conditions, as well as the bulk adhesive's sensitivity to strain rate [10]. In polyimide adhesive, thickness affects the strength and shear stress [11].

Adhesive can be a stand-alone connection or can also be a hybrid connection with ordinary mechanical fasteners. Such as adhesive with rivets or adhesive with welding. The adhesive increases the shear strength of the hybrid joint. However, the high temperature during welding makes the adhesive at the weld point peel off [12].

Research on bi-adhesive has been carried out on single lap joints with various loading levels and different adhesive ratios. [13]. Three-dimensional refinement was also carried out [14].

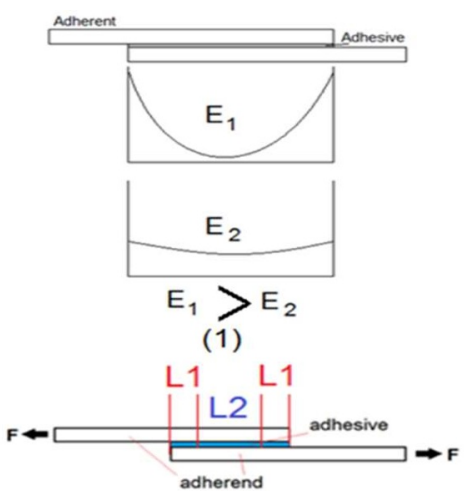

(2)

Fig.1. Comparison of the Shear Stress Distribution in Adhesive Joints with Different Modulus of Elasticity (1) and Bi-adhesive (2)

According to Volkersen's equation [15], the stress concentration factor (n), which is the ratio between peak shear stress $(\tau)$ and mean shear stress $(\bar{\tau})$, is influenced by shear modulus $(\mathrm{G})$ overlap length (l) and modulus of elasticity.

$$
n=\frac{\hat{\tau}}{\bar{\tau}}=\sqrt{\frac{G l^{2}}{2 E t \delta}}
$$

\section{Methodology}

Table 1. Material Properties

\begin{tabular}{llll}
\hline Material & $\begin{array}{l}\text { E } \\
(\mathrm{GPa})\end{array}$ & $\begin{array}{l}\text { Poisson } \\
\text { Ratio }\end{array}$ & $\begin{array}{l}\text { Yield } \\
(\mathrm{MPa})\end{array}$ \\
\hline $\begin{array}{l}\text { Adhesive } \\
\text { DP490 }\end{array}$ & 1.8 & 0.4 & 20 \\
\hline $\begin{array}{l}\text { Adhesive } \\
\text { ESP110 }\end{array}$ & 5.9 & 0.4 & 34 \\
\hline $\begin{array}{l}\text { Adherent } \\
\text { Aluminum }\end{array}$ & 71 & 0.33 & 280 \\
\hline
\end{tabular}

Modelling is completed by FEM. It begins with making a model of the adhesive connection in 2 dimensions and then meshing. The adhesive (w) width is prepared to vary $5 \mathrm{~mm}, 10 \mathrm{~mm}, 15 \mathrm{~mm}, 20$ $\mathrm{mm}, 25 \mathrm{~mm}$ and $30 \mathrm{~mm}$. Lap joint length is $14 \mathrm{~mm}$ with an adhesive thickness of $0.25 \mathrm{~mm}$. Then given a static load of $100 \mathrm{~N} / \mathrm{m}$

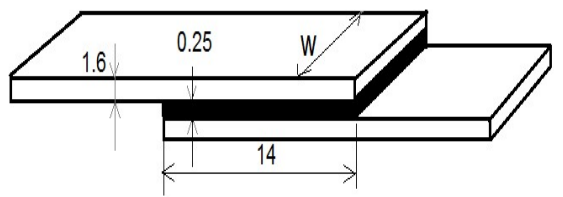

Fig.2. Specimen Dimensions, $w=5 \mathrm{~mm}, 10 \mathrm{~mm}, 15$ $\mathrm{mm}, 20 \mathrm{~mm}, 25 \mathrm{~mm}$ and $30 \mathrm{~mm}$

The discretization is carried out or dividing the continuum into small elements. The adhesive thickness is divided into five parts. Material properties are involved in the calculation. The boundary condition is determined by providing fixed support at one end of the adherent and applying tension to the other adherent.

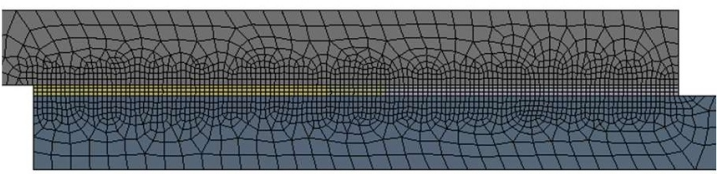

Fig.3. Meshing at Lap Joint

\section{Results And Discussion}

The results of the FEM simulation obtained the following stress distribution. It can be seen that at the end of the joining, there is a concentration of stress. A feature path is applied along the adhesive to obtain the stress value on the bond line, and a graph of the stress variation is obtained.

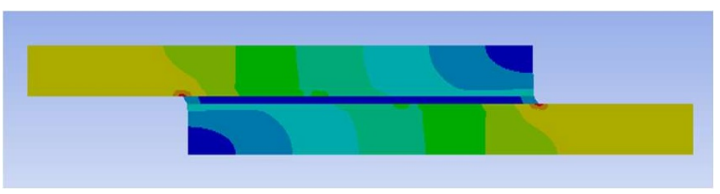

Fig.4. Stress Distribution in Single lap Joint by FEM 
The graph of the width relationship to the stress distribution can be seen as follows.

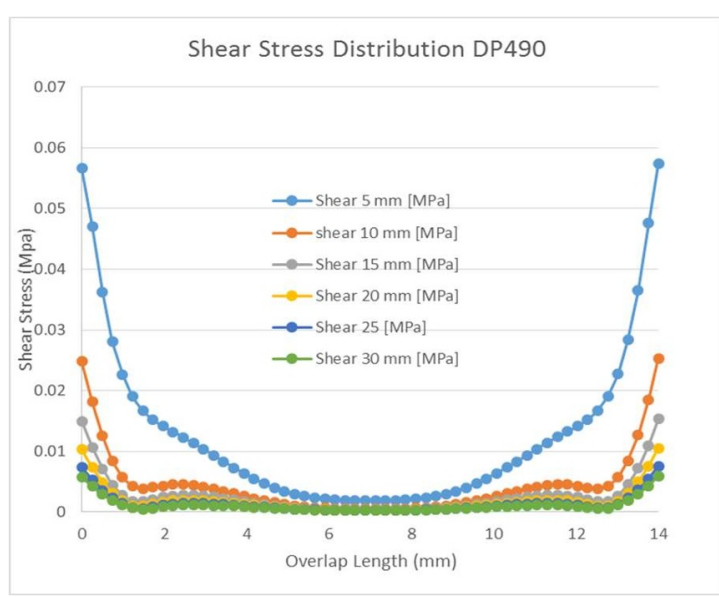

Fig.5. Shear Stress Distribution on bondline Single Adhesive DP490

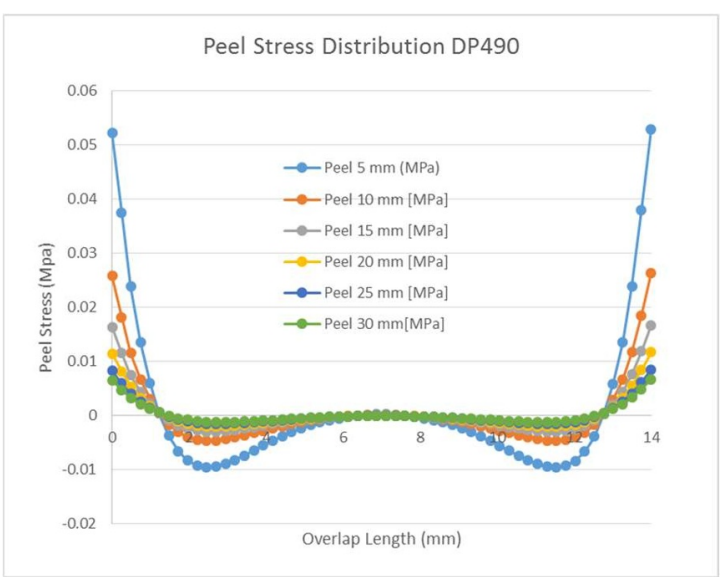

Fig.6 Peel Stress Distribution on bondline Single Adhesive DP490

Figures 5 and 6 show variations in the shear stress and peel stress of the DP490 adhesive due to changes in adhesive width. The higher of w value, the more even distribution will be.

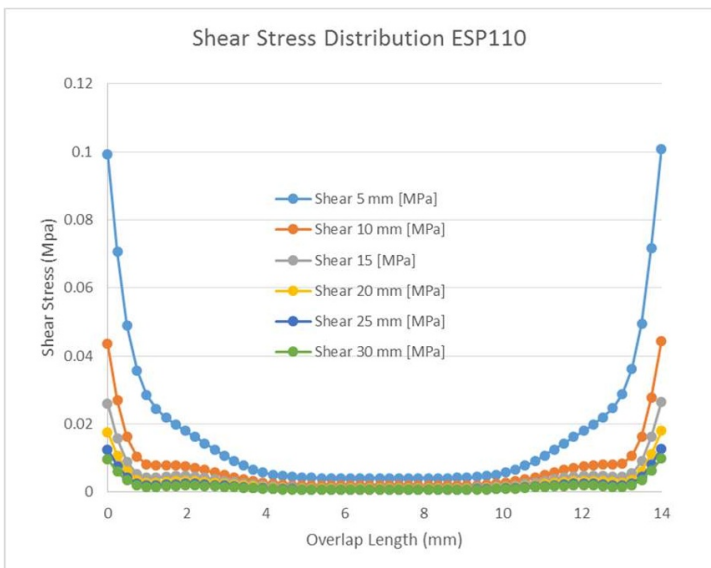

Fig.7. Shear Stress Distribution on bondline Single Adhesive DP490 ESP110

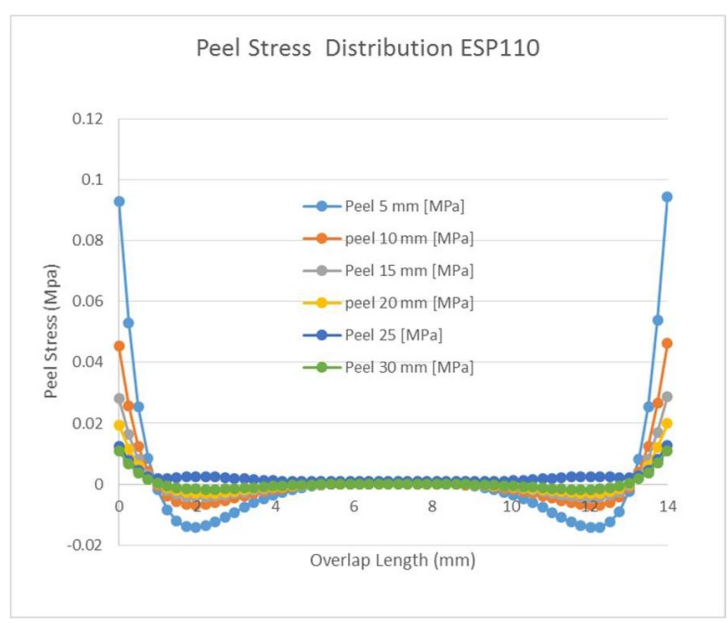

Fig. 8. Peel Stress Distribution on Bondline Single Adhesive ESP110

Figures 7 and 8 show changes in the shear stress and peel stress of the ESP110 adhesive due to the change in adhesive width. The higher the $\mathrm{w}$ value, the more even distribution will be. However, the peak stress on the ESP110 is higher than that of the DP490.

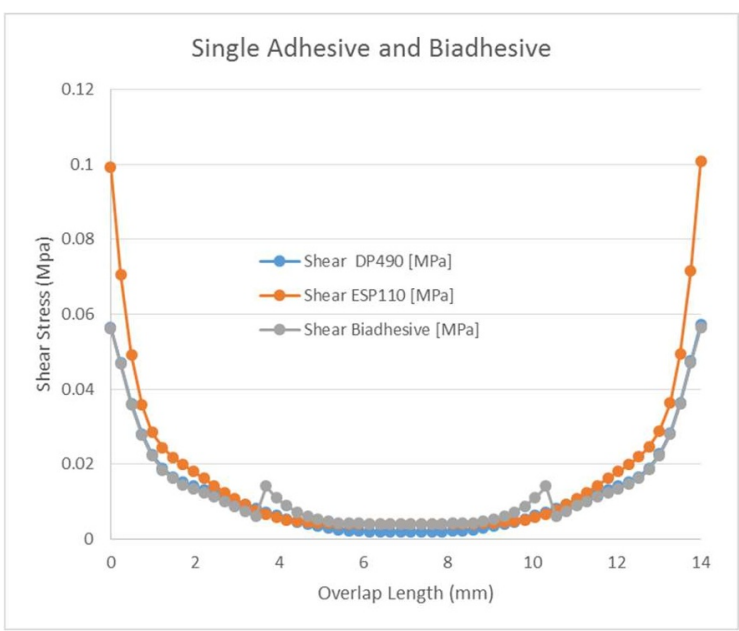

Fig.9. Comparison of Single Adhesive and Bi-adhesive Shear Stress

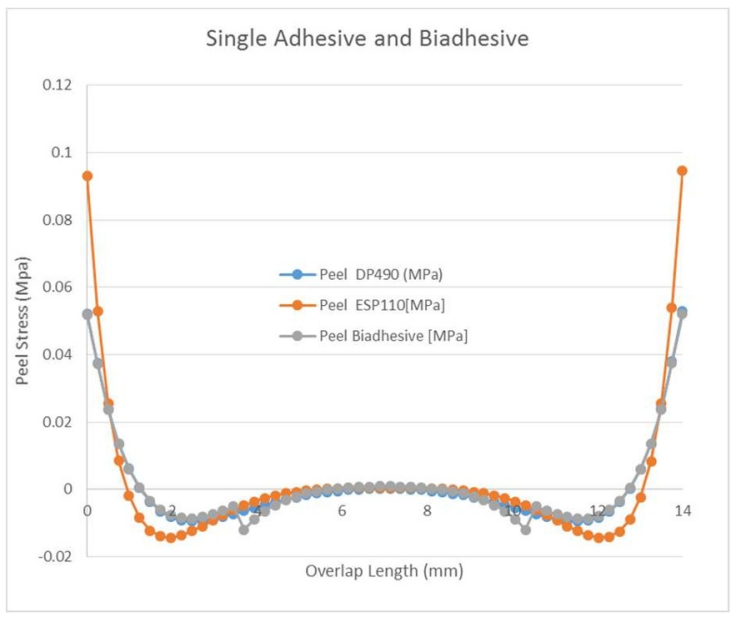

Fig.10. Comparison of Single Adhesive and Biadhesive Shear Stress 
From Figures 9 and 10, the shear stress and peel stress on the bi-adhesive have better distribution than the single adhesive individually. Installation of a more flexible adhesive at both ends of the connection will reduce the peak stress [13] [14].

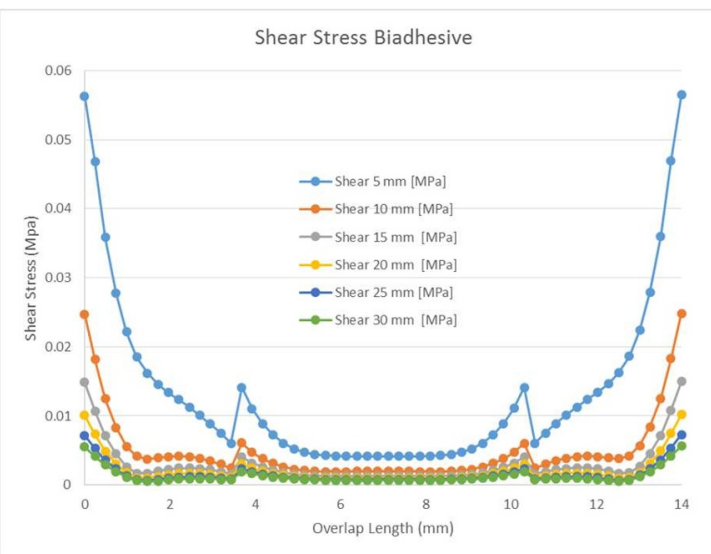

Fig.11. Shear Stress Distribution on Biadhesive DP490ESP110 Bond Line

Figure 11 shows the shear stress distribution on Biadhesive DP490-ESP110 with a length ratio of L1/L2 $=0.5$. In general, Bi-adhesive is better than single adhesive. The more expansive $\mathrm{w}$, the more even distribution will be. The comparison between the end of the joining and the middle is not high-pitched.

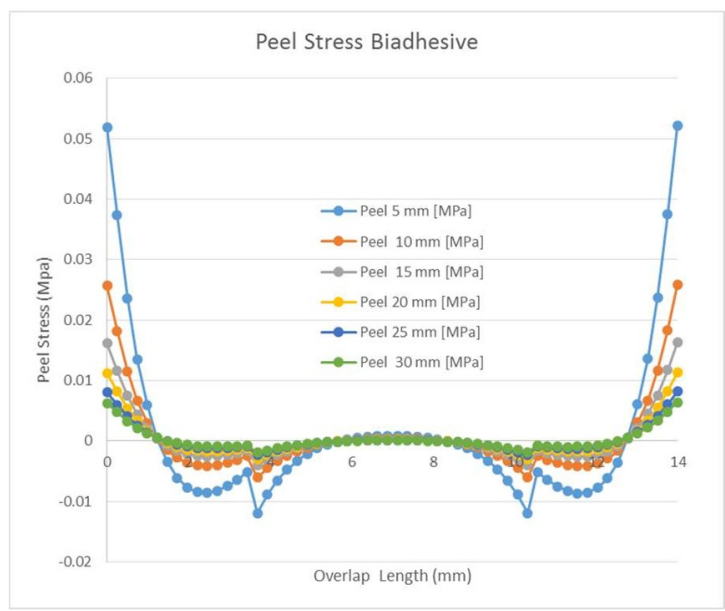

Fig.12. Peel Stress Distribution on Biadhesive DP490ESP110 Bond Line

Figure 12 shows the Peel Stress Distribution on Biadhesive DP490-ESP110 with a length ratio of L1/L2 $=0.5$. At a width of $5 \mathrm{~mm}$, there are very extreme conditions, namely the peel stress value is tremendous, both positive (tension) and negative (compression). In general, the peel stress is positive at the end of the joint, then drops drastically to zero after about $1 \mathrm{~mm}$ from the end, then negative and rises again to zero at the centre of the joint.

The results of the FEM analysis show that the modulus of elasticity of the adhesive significantly affects the stress distribution. This condition is following the Volkersen equation [15]. The width of the adhesive joint also affects the stress distribution at the adhesive joint. The bigger the distribution, the better.

\section{Conclusion}

The discussion above can be concluded that :

1. Biadhesive application on lap joints can improve shear stress and peel stress distribution on lap joints by employing a flexible adhesive at the end of the joint so that the peak stress will decrease.

2. The width of the adhesive joint significantly affects the stress distribution in general; the wider the distribution will be more sloping, while the smaller the stress distribution will be steeper.

\section{References}

[1] A. Pizzi, Phenolic resin adhesives, 2nd ed. New York, (2017).

[2] G. Di Bella, G. Galtieri, E. Pollicino, and C. Borsellino, "Mechanical characterization of adhesive joints with dissimilar substrates for marine applications," Int. J. Adhes. Adhes., vol. 41, pp. 33-40, (2013).

[3] M. Q. dos Reis, M. D. Banea, L. F. M. da Silva, and R. J. C. Carbas, "Mechanical characterization of a modern epoxy adhesive for automotive industry," J. Brazilian Soc. Mech. Sci. Eng., vol. 41, no. 8, pp. 1-11, (2019).

[4] B. Watson, Y. Nandwani, M. J. Worswick, and D. S. Cronin, "Metallic multi-material adhesive joint testing and modeling for vehicle lightweighting," Int. J. Adhes. Adhes., vol. 95, no. August, p. 102421, (2019).

[5] H. A. M. Araújo, J. J. M. Machado, E. A. S. Marques, and L. F. M. da Silva, "Dynamic behaviour of composite adhesive joints for the automotive industry," Compos. Struct., vol. 171, pp. 549-561, (2017).

[6] N. G. C. Barbosa, R. D. S. G. Campilho, F. J. G. D. Silva, and R. D. F. Moreira, "Comparison of different adhesively-bonded joint configurations for mechanical structures," Procedia Manuf., vol. 17, pp. 721-728, (2018).

[7] W. Polini and A. Corrado, "Effect of adherends misalignment on the strength of single-lap bonded joints," Int. J. Adv. Manuf. Technol., vol. 106, no. 3-4, pp. 817-828, (2020).

[8] F. Kadioglu and R. D. Adams, "Flexible adhesives for automotive application under impact loading," Int. J. Adhes. Adhes., vol. 56, pp. 73-78, (2015).

[9] S. C. Her, "Stress analysis of adhesively-bonded lap joints," Compos. Struct., vol. 47, no. 1-4, pp. 673-678, (1999).

[10] Y. Goda and T. Sawa, "Study on the effect of strain rate of adhesive material on the stress state in adhesive joints," J. Adhes., vol. 87, no. 7-8, pp. 766-779, (2011).

[11] K. Naito, M. Onta, and Y. Kogo, "The effect of adhesive thickness on tensile and shear strength 
of polyimide adhesive," Int. J. Adhes. Adhes., vol. 36, pp. 77-85, (2012).

[12] H. R. M. Costa, J. M. L. Reis, J. P. B. Souza, P. M. C. L. Pacheco, R. A. A. Aguiar, and S. De Barros, "Experimental investigation of the mechanical behaviour of spot weldingadhesives joints," Compos. Struct., vol. 133, pp. 847-852, (2015).

[13] I. Pires, L. Quintino, J. F. Durodola, and A. Beevers, "Performance of bi-adhesive bonded aluminium lap joints," Int. J. Adhes. Adhes., vol. 23, no. 3, pp. 215-223, (2003).

[14] S. Kumar and P. C. Pandey, Behaviour of Biadhesive joints, vol. 24, no. 7. (2010).

[15] Volkersen O., Rivet strength distribution in tensile-stressed rivet joints with constant crosssection. Luftfahrorschung, (1938). 